\title{
Metabolic syndrome and its components among university students in Kenya
}

\author{
Samuel Mungai Mbugua ${ }^{*}$, Samuel Thuo Kimani ${ }^{2}$ and Gilbert Munyoki ${ }^{3}$
}

\begin{abstract}
Background: Metabolic syndrome refers to a cluster of interrelated disorders which occur together causing an increase in the risk of developing cardiovascular disease and diabetes. The university population is an understudied group despite the increase in the frequency of related disorders and metabolic risk factors e.g. obesity and diabetes, majorly due to the assumption that they are in their most active phase of life therefore healthy. This study looked at metabolic syndrome, the sedentary lifestyles and dietary habits present among university students attending Mount Kenya University, main campus.

Methods: Stratified sampling was used to select participants. Self-administered questionnaires were issued to participants after a signed consent had been obtained following which clinical assessments and biochemical measures were performed. They included blood pressure, fasting blood glucose, triglycerides, high density lipoprotein-cholesterol, anthropometric measurements; height, weight, BMl and waist circumference. Pearson's chisquare tests and non-parametric independent t-test were used to analyze the prevalence of metabolic syndrome criteria per gender, the number of metabolic syndrome criteria per BMI and prevalence of metabolic syndrome criteria per BMI category.

Results: The study established that $1.9 \%$ of the participants met the criteria for diagnosis of metabolic syndrome according to HJSS criteria. Among the elements, there was statistical difference in gender BMI and waist circumference. $11.8 \%$ of subjects had two metabolic syndrome components while $3.1 \%$ had three components while none of the subjects had all six components. Elevated triglycerides was the most prevalent defining component for metabolic syndrome. There is a statistically significant relationship between sedentary lifestyle and dietary habits as risk factors to metabolic syndrome.
\end{abstract}

Conclusion: Young adults in university have begun developing metabolic syndrome and the risk of developing the syndrome continues to increase with the components being reported in early age. Educational initiatives to encourage healthy eating should be conducted within school premises in order to reinforce the message on healthy diets and physical exercise. Pre-admission screening to identify at risk students should be conducted. Targeted interventions development through a mandatory extra co-curricular program should be enforced to positively engage those at risk.

Keywords: Metabolic syndrome, University students, Diabetes

\footnotetext{
* Correspondence: samville7700@gmail.com

'Mount Kenya University, School of Nursing, Thika 342-01000, Kenya

Full list of author information is available at the end of the article
}

(c) The Author(s). 2017 Open Access This article is distributed under the terms of the Creative Commons Attribution 4.0 International License (http://creativecommons.org/licenses/by/4.0/), which permits unrestricted use, distribution, and reproduction in any medium, provided you give appropriate credit to the original author(s) and the source, provide a link to the Creative Commons license, and indicate if changes were made. The Creative Commons Public Domain Dedication waiver (http://creativecommons.org/publicdomain/zero/1.0/) applies to the data made available in this article, unless otherwise stated. 


\section{Background}

Metabolic syndrome (MS) refers to a combination of disorders which when they occur together increase the risk of developing cardiovascular disease and diabetes. It is a cluster of interrelated cardio-metabolic risk factors that include insulin resistance, lipid imbalance and hypertension [1-4]. Metabolic syndrome puts people at a much higher risk for heart attacks, strokes, complications of diabetes, and sudden cardiac death [5].

MS has become a public health concern currently and in future as a result of a rapid increase in childhood-teenage obesity and sedentary lifestyles putting young adults at risk [6]. A depiction of this in the developed world was reported in the 2003-2006 National Health and Nutrition Examination Survey (NHANES) in the US population that indicated a prevalence of metabolic syndrome in males and females as $20.3 \%$ and $15.5 \%$ respectively aged between 20 and 39 years [7]. Obesity among college students aged 18-29 years has increased significantly globally [8-10]. Studies have shown that the propensity of having one of the defining criteria for metabolic syndrome in college students in the United States was between $26 \%$ and $40 \%$ [11]. The prevalence of metabolic syndrome in children and adolescents in comparison to adults is relatively low, however overweight and obese adolescents have a prevalence of metabolic syndrome of up to $29 \%$ [12, 13]. Dysmetabolic syndrome in childhood and adolescence has also been proven to increase the risk of developing metabolic syndrome and cardiovascular disease [14].

Early detection of metabolic syndrome is critical for commencement of directed interventions leading to reduction in the risk of progression to metabolic syndrome, coronary heart disease and diabetes $[15,16]$. The risk factors for MS include central obesity, sedentary lifestyle, an elevated Body Mass Index (BMI), lack of physical exercise and poor dietary habits. Each of these factors has been shown to cause increased predisposition towards metabolic syndrome when they occur at an early age $[11,12]$.

Studies are required to understand the magnitude of the prevalence of MS among university students and despite the significant predisposition for obesity and other metabolic risk factors among university students, they remained a scarcely studied group and no study had been conducted in Kenyan universities.

Young people, aged 10-24 years constitute 36\% of the total population in Kenya forming a population of about 25.8 million [17]. Early prevention of preceding risk conditions and emphasis on change in lifestyle eating behaviors and attention to exercise would reduce progression to metabolic syndrome and other cardiovascular conditions later in life.

\section{Methods}

\section{Study population}

Participants in this cross-sectional study were recruited from Mount Kenya University, main campus, located in
Thika town on the outskirts of Nairobi, Kenya. The students attended university in Mount Kenya University in the main campus from all schools and were between the ages of 18-25 years. They were required to have enrolled in the regular mode of study with no previous chronic illness. Stratified sampling was employed with the stratification according to schools in the main campus. Participants were recruited through classroom announcements and word-of-mouth. 323 students were sampled to take part in the study. Signed consent was requested before taking part in the study. The questionnaires were number coded with each respondent having their own number assigned to them so as to ensure anonymity. Biochemical measures were collected and analysis performed with confidentiality assured.

\section{Lifestyle and health data}

Data on socio-demographics, sedentary lifestyle and dietary habits was collected using self-administered questionnaires at the Nursing Skills laboratory on arrival for screening following a 12-h fasting exercise.

After a five minutes rest, a self-administered questionnaire earlier developed and validated was distributed to consenting participants and once they finished filling them, biochemical measures, anthropometric measurements of Body Mass Index and waist circumference were conducted. The biochemical measures and anthropometric measurements were performed by a trained nurse.

Weight, height, waist and hip circumference were performed by qualified nurse. Height was taken using a Seca Rod 220 stadiometer (Seca, Hamburg, Germany), weight using a TANITA weighing scale (TANITA, Arlington Heights, Illinois) and waist circumference using a Gulick tape measure. The participants were required to wear light clothing, no shoes and with or without socks during weighing. BMI was calculated using the formula: weight in kilograms/height in meters squared $\left(\mathrm{kg} / \mathrm{m}^{2}\right)$ and the WHO guidelines on body mass index were utilized. Waist circumference was measured at the top of the iliac crest upon exhalation. Systolic and diastolic blood pressure was taken flowing a five minutes rest on arrival using an automated monitor. The participating students were given a copy of their individual results and the health take in the findings.

\section{Biochemical measures}

Following a 12-h minimum fast, fasting blood samples were assayed by standard methods for glucose, HDLcholesterol and triglycerides. The blood samples were analyzed using a SD Cholesterol/Lipid desktop biosensor analyzer. The point-of-care SD Biosensor analyzer gives a lipid profile and glucose levels in three minutes. Participants were each given a copy of their results and for those whose values were outside normal parameters, 
they were referred for follow up with their healthcare provider.

\section{Metabolic syndrome diagnosis criteria}

The following criteria stipulated by the Harmonized Joint Scientific Statement (HJSS) on metabolic syndrome were used [18]. Blood pressure- $>130 / 85$ mmHg. (Hypertension), Impaired glucose handling-PG $>200 \mathrm{mg} / \mathrm{dL}$ $(11.1 \mathrm{mmol} / \mathrm{L})$, raised fasting plasma glucose $>100 \mathrm{mg} / \mathrm{dL}$ ( $>5.6 \mathrm{mmol} / \mathrm{L}$ ), Waist circumference: $>94 \mathrm{~cm}$ (male) $>80 \mathrm{~cm}$ (female), Body mass index $>30 \mathrm{~kg} / \mathrm{m}^{2}$, Dyslipidemia: triglycerides (TG): $\geq 1.7 \mathrm{mmol} / \mathrm{L} / 150 \mathrm{mg} / \mathrm{dL}$ and high-density lipoprotein cholesterol $(\mathrm{HDL}-\mathrm{C}) \leq 1.0 \mathrm{mmol} /$ $\mathrm{L} / 40 \mathrm{mg} / \mathrm{dL}$ (male), $\leq 1.3 \mathrm{mmol} / \mathrm{L} / 50 \mathrm{mg} / \mathrm{dL}$ (female). To make a diagnosis of metabolic syndrome, the study considered any three characteristic abnormalities.

\section{Statistical analysis}

Statistical Package for Social Sciences (SPSS) version 22.0 was used for analysis. Demographics were calculated using means and frequencies. Analysis of variance (ANOVA) scores on the means procedure were used to examine differences between all anthropometric, clinical and biochemical parameters. Pearson's chi-square tests and non-parametric independent t-test were used to analyze the point prevalence of metabolic syndrome criteria per gender, the number of metabolic syndrome criteria per BMI and prevalence of metabolic syndrome criteria per BMI category. The $p$-value was set at 0.05 to test for significance in all tests.

\section{Results}

Demographics on the participants, individual defining criteria of metabolic syndrome, anthropometric, clinical and biochemical parameters in males and females are shown in Table 1.

Out of the 323 students participating in the study, majority $64.1 \%(n=207)$ were female and $35.9 \%(n=116)$ were male. The mean age for males was 23.2 years $(\mathrm{SD}=4.0)$ while the mean for females was $21.8(\mathrm{SD}=2.7)$ (Table 2).

It was established that elevated triglycerides was the most prevalent defining criteria for metabolic syndrome with $24.8 \%$ of the subjects diagnosed with the symptom. Low high density lipoprotein cholesterol was the second most prevalent defining criteria for metabolic syndrome, followed by impaired fasting glucose and high blood pressure respectively. $69.3 \%$ of the subjects were in the

Table 1 Anthropometric, clinical, and biochemical description of the subjects ${ }^{\mathrm{a}}$

\begin{tabular}{|c|c|c|c|c|}
\hline Characteristics & Gender & $\mathrm{N}$ & Mean & Std. deviation \\
\hline \multirow[t]{2}{*}{ Age (Years) } & Male & 116 & 23.2 & 4.0 \\
\hline & Female & 207 & 21.8 & 2.7 \\
\hline \multirow[t]{2}{*}{ BMI $\left(\mathrm{Kg} / \mathrm{m}^{2}\right)$} & Male & 116 & 21.7 & 3.1 \\
\hline & Female & 207 & 23.3 & 3.9 \\
\hline \multirow[t]{2}{*}{ Waist circumference (Cm) } & Male & 116 & 77.7 & 7.2 \\
\hline & Female & 207 & 77.4 & 9.4 \\
\hline \multirow[t]{2}{*}{ Systolic Blood Pressure (mmHg) } & Male & 116 & 128.3 & 12.5 \\
\hline & Female & 207 & 116.8 & 12.5 \\
\hline \multirow[t]{2}{*}{ Diastolic Blood Pressure (mmHg) } & Male & 116 & 75.1 & 9.5 \\
\hline & Female & 207 & 74.1 & 8.4 \\
\hline \multirow[t]{2}{*}{ Fasting blood glucose (mmd/l) } & Male & 116 & 4.8 & 0.6 \\
\hline & Female & 207 & 5.1 & 3.2 \\
\hline \multirow[t]{2}{*}{ Triglycerides (mg/dl) } & Male & 116 & 122.6 & 67.7 \\
\hline & Female & 207 & 115.9 & 72.1 \\
\hline \multirow[t]{2}{*}{ High Density Lipoprotein (HDL) cholesterol (mg/dl) } & Male & 116 & 58.1 & 20.7 \\
\hline & Female & 207 & 59.5 & 18.1 \\
\hline \multirow[t]{2}{*}{ Total cholesterol (mg/dl) } & Male & 116 & 152.6 & 38.1 \\
\hline & Female & 207 & 171.4 & 38.5 \\
\hline \multirow[t]{2}{*}{ Low Density Lipoprotein (mg/dl) } & Male & 116 & 71.3 & 32.6 \\
\hline & Female & 207 & 76.8 & 39.1 \\
\hline \multirow[t]{2}{*}{ Non - High Density lipoprotein (mg/dl) } & Male & 116 & 114.8 & 37.5 \\
\hline & Female & 207 & 102.4 & 41.2 \\
\hline
\end{tabular}

${ }^{a}$ Analysis of Variance (Anova) 
Table 2 Represents the independent T-test results for equality of means of the defining criteria ${ }^{a}$

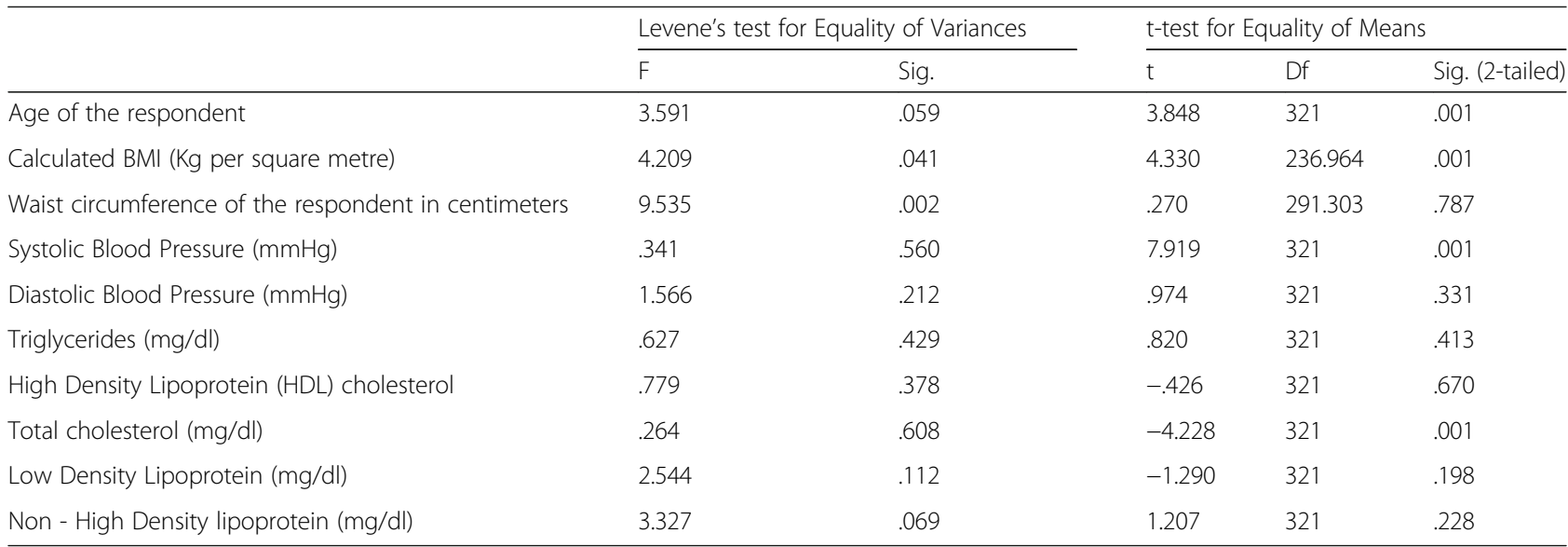

Independent t-test

normal range; however $3.7 \%$ were obese and $19.5 \%$ were overweight (Table 1).

The study established that $1.9 \%$ of the subjects met the Harmonized Joint Scientific Statement on Metabolic syndrome criteria for diagnosis of metabolic syndrome with a confidence interval $(\mathrm{CI})$ of $95 \%$. In regards to gender differences, it was established that out of the six subjects diagnosed with metabolic syndrome, five were females while only one was a male. Of the six subjects that were diagnosed with metabolic syndrome, four were obese, two were overweight and none was in either the normal weight category or underweight category (Fig. 1). The relationship between BMI and metabolic syndrome was statistically significant, ${ }^{1}(p<.001)$.

It was established that $50.2 \%$ of the female subjects recorded at least one component of metabolic syndrome which was slightly higher than that of their male counterparts at $45.7 \%$ (Fig. 2).
$5.8 \%$ of the females' subjects had a high waist circumference compared to $0.9 \%$ of their male counterparts. The percentage of females that had a high waist circumference was six times as much as the percentage of males (Fig. 3). The difference in waist circumference between the genders was statistically significant $(p<0.05)$.

$77.6 \%$ of the males were within the normal weight, $12.1 \%$ were overweight, $9.5 \%$ were underweight and $0.9 \%$ were obese. $69.3 \%$ of females were within the normal weight range, $19.5 \%$ were overweight, $7.4 \%$ were underweight and $3.7 \%$ were obese. The relationship between BMI and gender was statistically significant $(p=0.008)$.

In order to assess sedentary lifestyle physical exercise, sleep duration, snacking habits and normal daily activity were considered in the self-administered questionnaire. $61.3 \%$ of the respondents reported that they did not exercise frequently (Fig. 4). The average sleep duration for

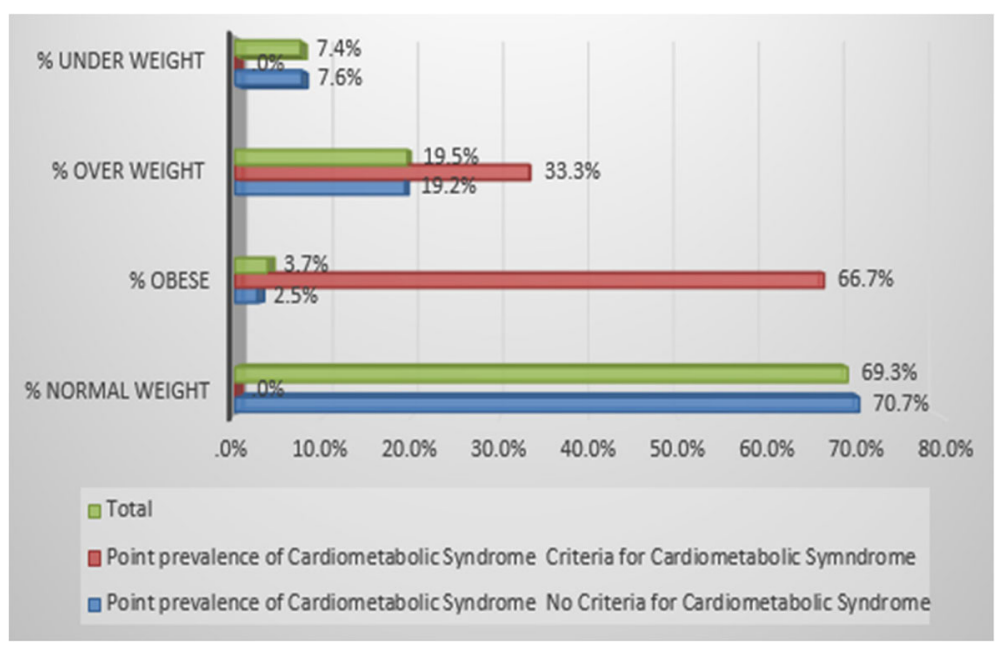

Fig. $1 \mathrm{BMl}$ Category and point prevalence of Metabolic syndrome 


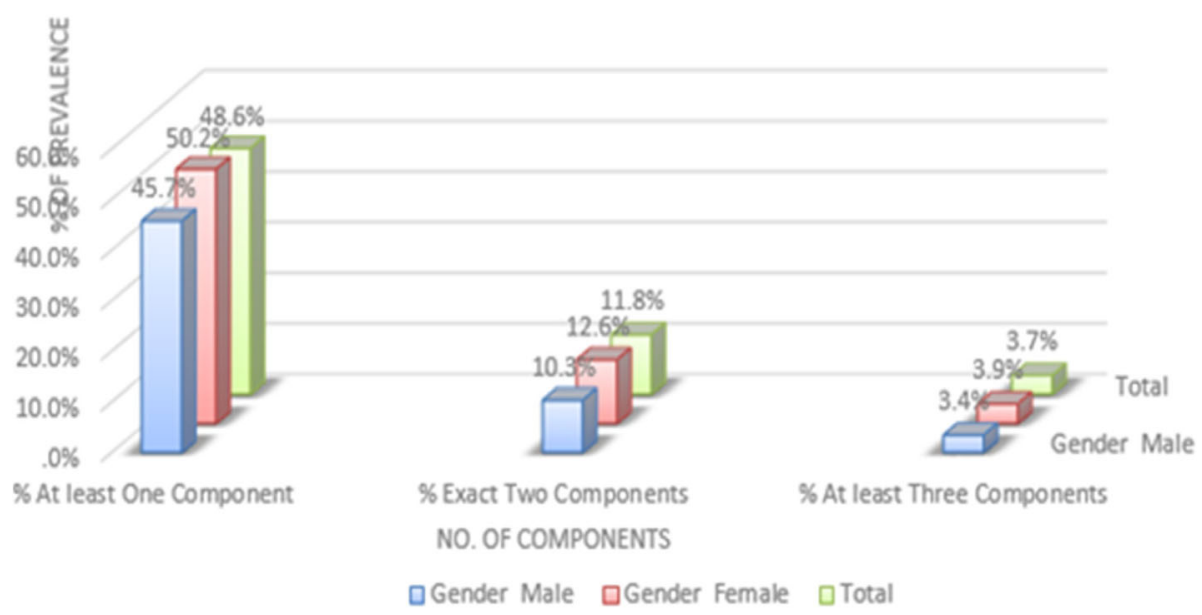

Fig. 2 Gender differences in regard to prevalence of metabolic syndrome components

$52.9 \%$ of respondents was 7 to 8 h with $31.3 \%$ reporting 5 to 6 h. $52.3 \%$ indicated limited activity in their day and $72.8 \%$ snacked on various processed foods while watching television or on their computers. The relationship between sedentary lifestyle as a risk factor and metabolic syndrome was statistically significant, $\left(\chi^{2}=8.221, \mathrm{df}=2\right.$, $p=0.016)$.

Data on diet and dietary habits showed that only $13.3 \%$ of the participants reported good nutritional intake while the remaining $84.7 \%$ were concerned about their nutritional status. $9.3 \%$ of respondents had poor eating habits. $85.4 \%$ of participants were not aware of the amount of calories consumed in a day. $32.8 \%$ of respondents reported to take at least one soft drink in a day (Fig. 5). The relationship between dietary habits as a risk factor and metabolic syndrome was statistically significant, $\left(\mathrm{X}^{2}=39.881, \mathrm{df}=4, p<0.001\right)$.

\section{Discussions}

There is a general misconception that young adults in ages between 18 and 25 years are healthy but despite this metabolic syndrome is present with $1.9 \%$ of the sample having MS. The most prevalent defining criteria was elevated triglycerides (24.8\%) followed by low high

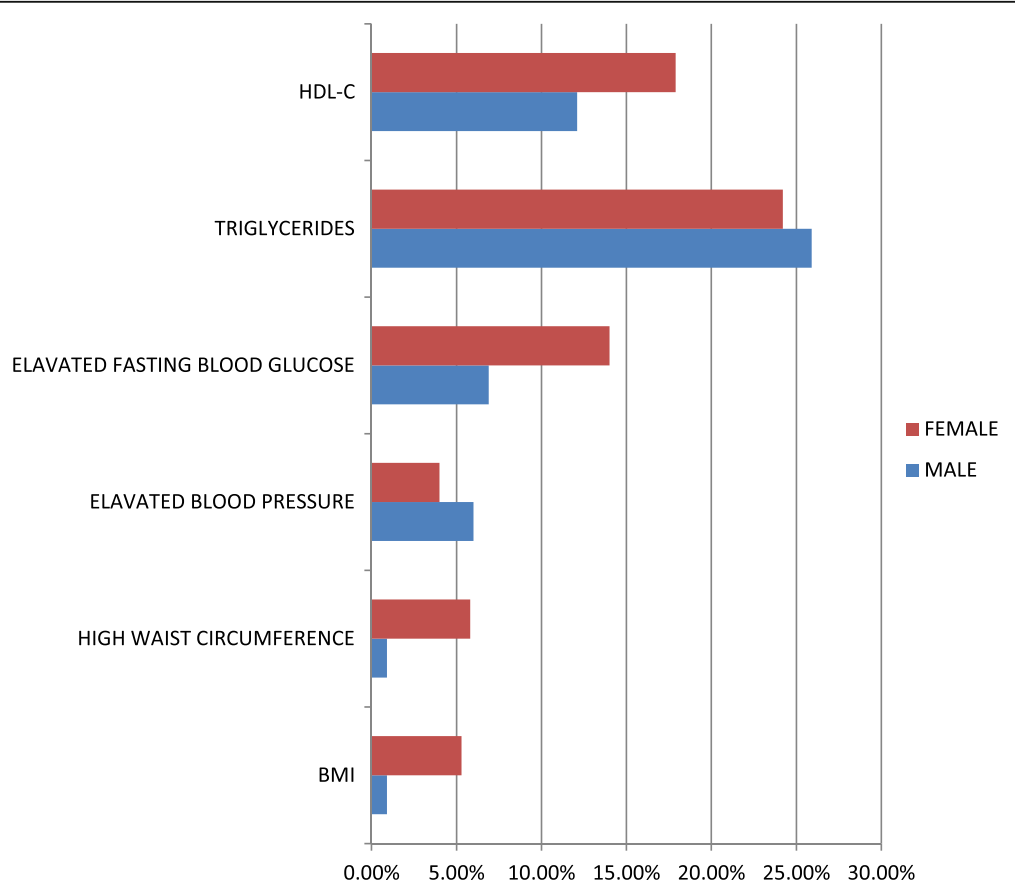

Fig. 3 Gender differences in regards to elevated metabolic syndrome elements 


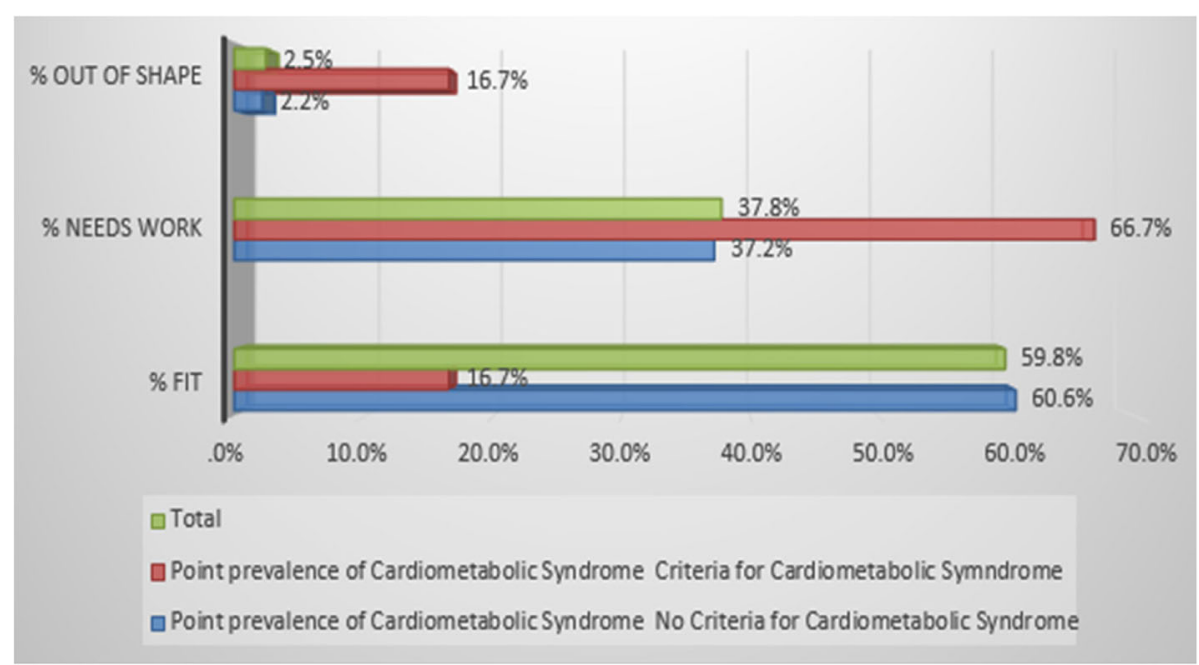

Fig. 4 Sedentary lifestyle and point prevalence of Metabolic syndrome

density lipoprotein cholesterol (15.8\%) with high waist circumference being the least prevalent. This is similar to studies by Huang et al., Dalleck \& Kjelland and Fernandes \& Lofgren $[11,12,15]$. Significantly more females were found to meet MS diagnosis criteria compared to their male counterparts. Though there is an impression that university students are healthy, this study reveals an occurrence of MS in these young adults and necessity for extensive health screening, education and sensitization to reduce the progression towards MS.

The prevalence of MS identified in this sample population correlates with similar studies of Huang et al. (1.7\%) and Fernandes \& Lofgren $(3.7 \%),[11,15]$. It was lower than the findings by Tope \& Rogers $(9.3 \%)$ and Yen et al. $(4.6 \%)[8,19]$. This can be attributed to differences in lifestyle choices and dietary habits as most of the studies were carried out in the USA and none in Eastern Africa. Morell et al. reported higher metabolic syndrome prevalence in males than in the females [20]. This could be speculated as a result of differences in socio-economic backgrounds and race. $32.8 \%$ of the subjects had one component of metabolic syndrome, $11.8 \%$ had two components and $3.1 \%$ had three components. This is similar to studies by Tope \& Rogers and Fernandes \& Lofgren $[8,15]$. This emphasizes the need for health screening of university students as additional defining criteria could develop later in life resulting from sedentary lifestyle and poor dietary habits.

The relationship between gender and waist circumference is statistically significant with more females having a high waist circumference compared to the males; similarly, there is statistical significance between systolic BP

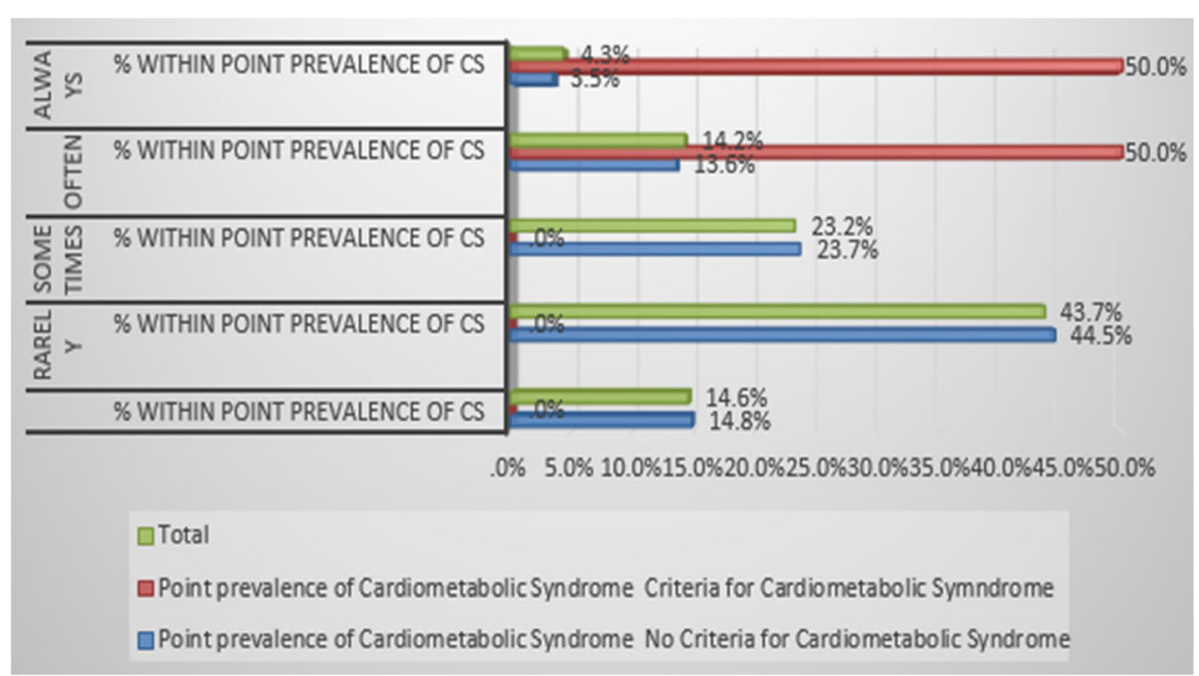

Fig. 5 Dietary Habits and Point prevalence of Metabolic Syndrome 
and gender but no significance between diastolic BP and gender. Although the percentage of female subjects with impaired fasting glucose was twice that of their male counterparts, similar to the findings by Huang et al., there is no statistical significance between gender and fasting blood glucose [11]. The study established that there is a statistically significant relationship between BMI and metabolic syndrome. Similarly, there is a statistically significant relationship between gender and body mass index with the number of females having an elevated BMI being four times more that of the males. This is similar to Tope \& Rogers [8]. It however differs from the findings by Huang et al. where the males were found to be more obese than the females [11]. This could be attributed to the demographical and socio-economical differences between the study populations. Gender differences in regard to overall prevalence of metabolic syndrome was established indicating a higher prevalence in females since out of the six subjects diagnosed with metabolic syndrome, five were females. Significance could not be tested as only one male met the MS criteria. This correlates to findings by Tope \& Rogers and Fernandes \& Lofgren $[8,13]$. The importance of screening and early intervention is critical in early management and prevention of MS in university students. This is partly because most of the sedentary lifestyle patterns and dietary habits in this stage of life persist later in adulthood increasing the likelihood of progression to MS indicating the significance of health screening in a university population.

\section{Conclusion}

This being one of the few studies on MS in university students in Africa and the first in Kenya, the prevalence of MS and each of the defining criteria is significantly high considering the predisposing risk to MS and chronic heart disease in later life. Educational initiatives on the importance of regular physical exercise and dietary modifications in terms of choices and habits are key in improving the cholesterol, triglyceride, glucose and HDL-C in the university population. Health screening measures are vital in the identification of at-risk young adults and the implementation of targeted interventional development. There is need for further research in this population to aid in development of a through screening and intervention policy for university students.

\section{Endnotes \\ ${ }^{1}$ Chi-square test}

\section{Abbreviations}

ANOVA: Analysis of Variance; BMI: Body Mass Index; BP: Blood pressure;

Cl: Confidence Interval; HDL-C: High density lipoprotein cholesterol;

MS: Metabolic syndrome; SPSS: Statistical Package for Social

SciencesDefinition of Terms
Young Adults: In this study, young adults are defined as persons aged 1825 years.; Sedentary lifestyle: A lifestyle characterized by little physical exercise, frequent/extended sleep, long durations of sitting, watching television, playing video games, using a computer/mobile phone, and is usually accompanied by snacking habits.; Dietary habits: Decisions made by an individual regarding choice of food, preferences, content (diet), calorie intake and frequency of consumption.

\section{Acknowledgments}

We would like to thank the Directorate of Research, Mount Kenya University for their support during this study. We would like to appreciate all the participants who took part in this study.

\section{Funding}

No funding was obtained for this study.

\section{Availability of data and materials}

The datasets used and/or analyzed during the current study are available from the corresponding author on reasonable request.

\section{Authors' contributions}

All authors were instrumental in conception, research development and study design. SM contributed in data collection. ST was instrumental in statistical analysis. GM contributed in discussion and manuscript revision. All authors read and gave final approval for the manuscript's submission and publication.

\section{Ethics approval and consent to participate}

Ethical approval was sought from Mount Kenya University Ethical and Research Committee. The research permit was obtained from the National Commission for Science, Technology and Innovation (NACOSTI). The researchers sought and explained the content of the consent document to study participants with assurance of confidentiality.

Consent for publication

Not applicable.

\section{Competing interests}

The authors declare that they have no competing interests.

\section{Publisher's Note}

Springer Nature remains neutral with regard to jurisdictional claims in published maps and institutional affiliations.

\section{Author details}

'Mount Kenya University, School of Nursing, Thika 342-01000, Kenya. ${ }^{2}$ University of Nairobi, College of Health Sciences, School of Nursing Sciences, P.O Box 19676, KNH, Nairobi, Kenya. ${ }^{3}$ Kenyatta University, School of Medicine, P.O Box 43844, Nairobi 00100, Kenya.

Received: 7 September 2017 Accepted: 22 November 2017

Published online: 28 November 2017

References

1. Grundy SM, Cleeman JI, Daniels SR, Donato KA, Eckel RH, Franklin BA, Spertus JA. Diagnosis and management of the metabolic syndrome. Circulation. 2005;112(17):2735-52.

2. Reaven GM. Role of insulin resistance in human disease. Diabetes. 1988 . 37(12):1595-607.

3. Alberti G. Introduction to the metabolic syndrome. Eur Heart J Suppl. 2005; 7(suppl D):D3-5.

4. Alberti KGM, Zimmet P, Shaw J. The metabolic syndrome-a new worldwide definition. Lancet. 2005;366(9491):1059.

5. Williams L. Third report of the National Cholesterol Education Program (NCEP) expert panel on detection, evaluation, and treatment of high blood cholesterol in adults (Adult Treatment Panel III) final report. Circulation. 2002:106(25):3143.

6. Weiss R, Dziura J, Burgert TS, Tamborlane WW, Taksali SE, Yeckel CW, Sherwin RS. Obesity and metabolic syndrome in children and adolescents. N Engl J Med. 2004;350(23):2362-74. 
7. Marriott BP, Olsho L, Hadden L, Connor P. Intake of added sugars and selected nutrients in the United States, National Health and nutrition examination survey (NHANES) 2003-2006. Crit Rev Food Sci Nutr. 2010; 50(3):228-58.

8. Topè AM, Rogers PF. Metabolic syndrome among students attending a historically black college: prevalence and gender differences. Diabetol Metab Syndr. 2013;5(1):2.

9. Morrell JS, Lofgren IE, Burke JD, Reilly RA. Metabolic syndrome, obesity, and related risk factors among college men and women. J Am Coll Heal. 2012; 60(1):82-9.

10. Poobalan A, Aucott L. Obesity among young adults in developing countries: a systematic overview. Curr Obes Rep. 2016;5(1):2-13.

11. Huang TTK, Kempf AM, Strother ML, Li C, Lee RE, Harris KJ, Kaur H. Overweight and components of metabolic syndrome in Collge students. Diabetes Care. 2004;27(12):3000-1.

12. Dalleck LC, Kjelland EM. The prevalence of metabolic syndrome and metabolic syndrome risk factors in college-aged students. Am J Health Promot. 2012;27(1):37-42

13. Luk AO, So WY, Ma RC, Kong AP, Ozaki R, Ng VS, Chan JC. Metabolic syndrome predicts new onset of chronic kidney disease in 5,829 patients with type 2 diabetes. Diabetes Care. 2008;31(12):2357-61.

14. Bitsori M, Kafatos A. Dysmetabolic syndrome in childhood and adolescence. Acta Paediatr. 2005;94(8):995-1005.

15. Fernandes J, Lofgren IE. Prevalence of metabolic syndrome and individua criteria in college students. J Am Coll Heal. 2011;59(4):313-21.

16. Mokdad AH, Ford ES, Bowman BA, Dietz WH, Vinicor F, Bales VS, Marks JS. Prevalence of obesity, diabetes, and obesity-related health risk factors. JAMA. 2003;289(1):76-9.

17. Kenya National Bureau of Statistics (KNBS) and ICF Macro. Kenya demographic and health survey 2008-09. Calverton: KNBS and ICF Macro; 2010.

18. Alberti KGMM, Eckel RH, Grundy SM, Zimmet PZ, Cleeman Jl, Donato KA, Smith SC. Harmonizing the metabolic syndrome. Circulation. 2009;120(16): 1640-5

19. Yen SL, Chiu TY, Lin YC, Lee YC, Lee LT, Huang KC. Obesity and hepatitis B infection are associated with increased risk of metabolic syndrome in university freshmen. Int J Obes. 2008;32(3):474

20. Morrell JS, Cook SB, Carey GB. Cardiovascular fitness, activity, and metabolic syndrome among college men and women. Metab Syndr Relat Disord. 2013;11(5):370-6.

\section{Submit your next manuscript to BioMed Central and we will help you at every step:}

- We accept pre-submission inquiries

- Our selector tool helps you to find the most relevant journal

- We provide round the clock customer support

- Convenient online submission

- Thorough peer review

- Inclusion in PubMed and all major indexing services

- Maximum visibility for your research

Submit your manuscript at www.biomedcentral.com/submit 